АНДРЕЕВ Иван Андреевич - ассистент кафедры философии, политологии и социологии Национального исследовательского университета «Московский энергетический институт» (111250, Россия, г. Москва, Красноказарменная ул., 14; v-andreev_07@таil.ru)

\title{
«МЯГКАЯ СИЛА» НА ЗАПАДЕ И НА ВОСТОКЕ: ПРОБЛЕМА ЭФФЕКТИВНОСТИ
}

\begin{abstract}
Аннотация. В статье обсуждается вопрос о критериях оценки «мягкой силы». Доказывается невозможность пригодной для всех модели «мягкой силы», ибо практики ее применения определяются конкретными целями и задачами, которые у разных государств могут существенно различаться. Анализируя попытки основоположника теории «мягкой силы» Дж. Ная обосновать свое понимание данного феномена в качестве нормативного, автор статьи делает вывод, что критерием оценки «мягкой силы» может быть только эффективность. Проводится сопоставление американской и китайской стратегий «мягкой силы» в плане их результативности.
\end{abstract}

Ключевые слова: политическое влияние, «мягкая сила», имидж страны, международная среда, политическая стратегия

$\mathrm{K}$ числу специфических предрассудков и предубеждений, характерных и для западных политиков, и для западной политической науки, принадлежит уверенность в том, что так называемая мягкая сила является исключительным конкурентным преимуществом либеральных демократий западного типа. Так долгое время считал и основоположник теории «мягкой силы» Дж. Най. В своей наиболее известной книге «Мягкая сила. Средства добиваться успеха в мировой политике», где был дан первый развернутый набросок его теории политического влияния, есть упоминания и о странах Востока, но только вскользь и главным образом с точки зрения их восприимчивости К воздействию «мягкой силы» США. Между тем китайские политические аналитики разработали собственные, альтернативные западным подходам концепции «мягкой силы», используя в качестве их отправной точки понятие «могущественное культурное государство».

Так же, как и у Дж. Ная, эта модель включает в себя целый ряд компонентов, но, в отличие от американского коллеги, китайские авторы делают акцент не на форме политического устройства страны, а на культуре в широком понимании этого слова [Тимофеев 2009]. В последнее время руководящие круги КНР все более утверждаются в мысли, что «китайская мудрость» и многовековая культура древнейшей мировой цивилизации станут ключевым духовно-идеологическим фактором в создании принципиально новой геополитической конструкции - «сообщества единой судьбы». Едва ли надо специально пояснять, что «сборка» данной конструкции при этом понимается как особая историческая миссия КНР.

Этот новый взгляд на «мягкую силу» вызвал к жизни специфические практики и инструменты завоевания политических симпатий. Таковы, к примеру, так называемая буддийская дипломатия (Пекин патронирует священные центры буддизма и оказывает помощь в реставрации памятников буддийской культуры в разных странах Азии) или, допустим, тактика приобретения Китаем прав участия в известных зарубежных культурных брендах, что позволяет создавать ему репутацию страны, принимающей на себя ответственность за мировое классическое наследие.

Пример Китая показал, что страны, не принадлежащие к западной цивилизации, также располагают собственными, и нередко немалыми, ресурсами, 
которые, если использовать их, не оглядываясь на западные теории, могут конвертироваться в факторы «мягкой силы». Это примечательное для понимания динамики современного глобального мира открытие существенно повлияло на мировоззрение политических элит целого ряда незападных стран, прежде всего азиатских. Под его влиянием разрабатывались, планировались и осуществлялись успешные стратегии странового брендинга под красноречивыми девизами «Прекрасная Япония», «Динамичная Корея» и др. Индийские креативные специалисты из Национального института преобразования Индии (NITI) разработали комплекс взаимосвязанных имиджевых кампаний по продвижению привлекательного для зарубежных туристов и инвесторов образа Индии (Make in India, Incredible India, God's Own Country и др.) [Емельянова 2015]. Весь этот многообразный и разноплановый опыт очень интересен и поучителен. Тем не менее по концептуальной содержательности и уровню разработки теории «мягкой силы», а также по размаху своей пропагандистской работы КНР, на наш взгляд, занимает ведущее место среди стран, не принадлежащих к западному миру, во всяком случае среди тех из них, которые пытаются выстроить собственную модель «мягкой силы», не ориентированную на западные образцы как изначально нормативные.

В конце концов даже Дж. Най, наблюдая за расширением сферы политического влияния КНР, должен был скрепя сердце признать, что эта восходящая держава также обладает потенциалом «мягкой силы», который она не без успеха реализует. Но примечательно, что при этом он сделал ряд оговорок, и смысл их состоит в том, что китайцы все-таки не понимают истинной природы «мягкой силы», которая коренится в либеральном политическом порядке, а потому в этом плане они в принципе никак не смогут сравняться с привлекательностью «свободного мира» во главе с США 1 .

Без всякого преувеличения можно сказать, что в мире нет более известного и, как сейчас принято говорить, «раскрученного» специалиста по «мягкой силе», чем Дж. Най. Но, хотя его теоретические взгляды и экспертные заключения произвели в западной политической науке огромный резонанс, они, как ни странно, ни у нас, ни на Западе не подвергались системному методологическому анализу. Это не значит, что с его взглядами на проблемы политического влияния никто не полемизировал, но выставленные ему возражения затрагивали в основном лишь некоторые его обобщения и формулировки, только отдельные аспекты развиваемого им подхода, не поднимаясь при этом до уровня системного метаанализа и общей характеристики эпистемологического статуса его теории. Между тем с подачи Дж. Ная в западной политической науке утвердилась совершенно определенная - нормативистская трактовка «мягкой силы», которая по умолчанию рассматривается в качестве само собой разумеющейся и как бы естественной. В рамках данной трактовки оценка «мягкой силы» той или иной страны - это, по сути дела, оценка культурно-психологической дистанции между данной страной и нормативными западными образцами. При этом такая дистанция может определяться посредством различных социометрических измерений (как, например, при составлении известных рейтингов Soft Power Top 30, ежегодно публикуемых британским агентством Portland Communications), что придает таким оценкам видимость полной объективности [Андреев 2020].

Было бы неверным отрицать, что порой такого рода оценки могут быть эвристически полезными, поскольку иной раз они позволяют высветить сильные

1 Nye J. 2012. China's Soft Power Deficit. - The Wall Street Journal. May 8; Nye J. 2013. What China and Russia Don’t Get about Soft Power. - Foreign Policy. April 29. 
и слабые стороны имиджа той или иной страны, хотя при этом непременно следует уточнять - имиджа, который складывается при восприятии «с Запада» (или, если рассуждать в рамках известного противоречия между промышленно развитой частью мира и так называемым глобальным Югом, «с Севера»). Между тем такая точка наблюдения не является единственно возможной и, тем более, единственно верной, ведь наряду с Западом и Севером, как известно, существуют и другие части света, среди которых особое место занимает возрождающийся и поднимающийся Восток. А потому методика сравнительных оценок, в основу которых положены нормативистские модели «мягкой силы», основанные на теоретических подходах Дж. Ная, в целом никак не может быть признана ни вполне адекватной, ни реалистической в том смысле, в каком понятия «реализм» и «реалистический» применимы в политике в соответствии c eе, политики, внутренними законами.

Все дело в том, что, оценивая потенциал мирового влияния различных стран, Дж. Най, а вместе с ним и другие ориентированные на англоязычную политическую науку эксперты и аналитики рассматривает состав и структуру «мягкой силы» весьма отвлеченно - по сути дела, не обращая внимания на то, что геополитические субъекты «мягких влияний» могут ставить перед собой разные задачи и, соответственно, выступать при этом в разных имиджевых ролях. Во всяком случае, не только в качестве некоего глобального «ментора», генерирующего многочисленные морализаторские сентенции на темы демократии и международного порядка, «основанного на правилах». Ведь, помимо «соблазнения» привлекательными для многих сторонами западного образа жизни, о котором пишет Дж. Най (соблазнение - seduction - это именно его термин), существуют и другие причины психологического притяжения, побуждающие к тому, чтобы идентифицировать себя с другими субъектами. И такие причины особенно многообразны и действенны за пределами западного мира: сознание религиозной близости (которое в постхристианской Европе почти совершенно утрачено), ощущение этнического родства с взаимным переносом самоидентификаций (например, между турками и другими тюркоязычными народами), сходный опыт преодоления колониализма и осуществления догоняющей модернизации, порождающий своеобразную азиатскую, африканскую и вообще «постколониальную» солидарность. Во всех перечисленных и подобных им случаях мы, в сущности говоря, также имеем дело с феноменом «мягкой силы», но ее генезис, композиция элементов, ее образующих, а также формы ее проявления могут существенно различаться. Поэтому следование западным рецептам применения «мягкой силы» на Востоке никак не может принести такого же успеха, как на Западе. Осознавая это, политические элиты стран Юго-Восточной и Южной Азии, а также Ближнего Востока ищут собственные пути и вырабатывают разнообразные стратегии «мягкого» влияния, рассчитанные на собственные возможности. И единственным критерием успеха или неуспеха таких поисков и выработанных в ходе этих поисков политических стратегий должно признаваться не соответствие (или несоответствие) какой-то «образцовой» модели, а эффективность в решении задач, поставленных политическим руководством данной страны. Кроме того, сопоставление потенциалов «мягкой силы» представляет собой не статичное, а динамичное соотношение, поэтому его надо рассматривать с учетом складывающейся тенденции и возможной перспективы.

В этой связи особенно интересен политический опыт КНР, которая в настоящее время является единственной азиатской страной, обладающей не только значительным (по сути дела - самым большим на Азиатском континенте) политическим влиянием глобального масштаба, но и не менее значительным 
научным потенциалом, позволяющим самостоятельно разрабатывать теорию «мягкой силы» и принципы ее применения в международных отношениях и внутри страны.

Что же думают по поводу критериев действенности «мягкой силы» сами китайцы, как они оценивают свои политические стратегии на фоне аналогичных стратегий Запада? Надо сказать, что китайские политологи в полной мере признают, что здесь США пока доминируют, и даже разработали определенную методику количественного сопоставления «мягкой силы» США и КНР. По их подсчетам, соотношение сил в этой области составляет примерно $8: 1$ [Журавлева 2016]. Тем не менее подходы, которых придерживаются китайские эксперты и аналитики, отличаются большей гибкостью и практичностью, чем те, которые отличают западные политические круги и западную политическую науку, развивающую довольно догматичную модель, разработанную Дж. Наем, а затем им же трансформированную в концепцию «умной силы». В китайских публикациях на эту тему нет абсолютизации какой-то универсальной модели «мягкой силы», и допускается значительное разнообразие, которое делает возможным ситуацию, которую можно охарактеризовать как параллельное доминирование. При параллельном доминировании преобладание «мягкой силы» каких-то государств и/или межгосударственных объединений не абсолютно; обычно оно проявляется лишь в некоторых аспектах и не исключает одновременного возвышения других стран-лидеров, чья привлекательность проявляется иначе и затрагивает какие-то иные психологические потребности членов мирового сообщества.

В китайских публикациях признается вклад Запада в мировую культуру, в особенности в прогресс науки и технологий, в создание основ современной демократии, в разработку концепции прав человека и защиту самих этих прав. Но все же главной ценностью для западного мира, по мнению большинства китайских авторов, является материальный (особенно финансовый) успех, что неизбежно ведет его к непреодолимому духовному кризису и моральной деградации. Конечно, в этом плане не идеальны и китайцы, но в принципе в китайской традиции заложены иные ориентиры и ценности, прежде всего - подчинение индивидуалистических устремлений коллективному благу, поэтому в современных условиях именно китайская культура могла бы компенсировать то, чего не может дать западная цивилизация, и предложить альтернативу той всеобщей опасности расчеловечивания, которая присуща западной идеологии. У Запада, признают китайские авторы, надо учиться демократии, свободе, правам человека. Но западный человек придает слишком большое значение погоне за личной выгодой, и для того, чтобы избавиться от этой «ядовитой» склонности, ему следует обратиться к китайской традиционной мудрости как противоядию. Вместе с тем это столкновение ценностей, а значит, и противостояние различных типов «мягкой силы», согласно точке зрения китайских политических теоретиков, вовсе не обязательно должно обернуться вооруженным конфликтом между КНР и Западом во главе с США. По сути дела, Пекин выдвигает мирную программу корректировки современного мирового развития за счет широкого распространения китайского культурно-исторического опыта и сформировавшегося на почве этого опыта философии бытия.

Надо сказать, что Пекин тратит на реализацию своей стратегии наращивания «мягкого» влияния огромные финансовые ресурсы. Осуществляемые им проекты очень масштабны: достаточно, например, упомянуть в этой связи о глобальной сети институтов и классов Конфуция ${ }^{1}$. Их насчитывается ныне

${ }^{1}$ https://www.laowaicareer.com/blog/confucius-institute/ (проверено 06.07.2021). 
свыше 500, что количественно превосходит всю совокупность аналогичных учреждений, созданных в рамках культурно-образовательных проектов стран Западной Европы. Но дело не только в размахе китайских инициатив самих по себе. Китайцам нередко удается создавать мультипликативные эффекты, используя, как это принято в восточных единоборствах, энергию и ресурсы своих конкурентов и противников. Так, в частности, китайский капитал на правах соинвестора активно проникает в американский и европейский медиабизнес, тем самым получая доступ к зарубежным медиатехнологиям и коммуникативным сетям, по которым распространяется видеопродукция по всему миру. А благодаря регулированию доступа на китайский медиарынок зарубежных компаний Пекин получает возможность корректировать содержание кино- и видеопродукции, исключая нежелательные для Поднебесной мотивы.

И если использовать предложенный нами критерий оценки «мягкой силы» по получаемым политическим результатам, то надо отметить следующее. В целом, если не считать страны Запада во главе с США, для которых Поднебесная является главным глобальным конкурентом, политическая стратегия Пекина, комбинирующая «мягкую силу» с экономическими «приманками», вызывает в мире весьма позитивный отклик. В особенности это касается непосредственно соседствующих с КНР стран. КНР имеет статус партнера по диалогу с АСЕАН. Благодаря созданию Шанхайской организации сотрудничества (ШОС), одним из учредителей которой выступила КНР, была создана система многостороннего сотрудничества и на ее северных границах. Надо сказать, что даже страны, которые в культурно-политическом отношении принадлежат к западному миру (Новая Зеландия) или являются его близкими союзниками (Южная Корея, Япония, Таиланд и др.), не горят желанием включаться в те антикитайские торговые войны и другие политические кампании, которые развертывают в последнее время США, и, напротив, присоединяются к отдельным китайским геоэкономическим проектам.

Китай ведь не ставил перед собой задачу обеспечения тотального контроля над всем миром и повсеместного насаждения системы ценностей либерального капитализма. Его цель состояла в том, чтобы обеспечить процесс формирования вокруг Поднебесной стабильной и комфортной международной среды, безопасность экспортных путей (прежде всего морских) и точечный контроль над источниками необходимых для растущей китайской экономики ресурсов. Этот процесс не был гладким, что в значительной степени объясняется как раз тем, что в отдельных случаях использование Пекином инструментов «мягкой силы» уступало место демонстрациям военной мощи (в качестве примера сошлемся на действия КНР в Южно-Китайском море, где между несколькими государствами региона разгорелся спор из-за принадлежности ряда стратегически важных островов, обладание которыми обеспечивает контроль над значительными природными ресурсами). Тем не менее Поднебесной удалось за 30 лет создать ориентированную на ее запросы и потребности глобальную инфраструктуру сотрудничества, сопоставимую по масштабам и охвату с той, которая обеспечивает развитие США. Таким образом, если ориентироваться на официально декларируемые цели, сказанного, собственно говоря, достаточно, чтобы признать проводимую Пекином политику - вначале политику добрососедства, а потом и «мягкой силы» - в целом не менее успешной, чем американская политика создания глобальных союзов.

В то же время различными средствами, в т.ч. поощряя развитие и расширение академических обменов и предоставляя стипендии студентам из различных стран мира практически в тех же масштабах, что и США, Пекин стимулировал формирование ориентированных на него политических элит практически во 
всех важных для него развивающихся странах. В динамике привлекательность сотрудничества с Китаем, его «мягкая сила» демонстрирует противоречивые тенденции - в развивающихся странах она в основном восходящая, тогда как в США, Японии и целом ряде стран ЕС отношение к КНР ухудшается. Что же касается главного глобального конкурента Китая - США, то их имидж в глазах всего мира, не исключая и ближайших союзников, за последние несколько лет заметно померк. Разумеется, значительную роль в этом сыграли импульсивные и непредсказуемые действия Д. Трампа. Но дело не только в нем лично. Трамп лишь ускорил то, что подспудно созревало уже давно. Стала очевидной эрозия главного компонента «мягкой силы» США - казавшейся многим образцовой американской демократии, которая на поверку оказалась хрупкой и неэффективной, что вынуждены признавать самые авторитетные зарубежные эксперты. Американские политические партии стали проявлять сектантскую непримиримость, превращаясь, по выражению Ф. Фукуямы, в противостоящие друг другу и ненавидящие друг друга «политические племена» 1 . Так что никакая широко разрекламированная система «сдержек и противовесов» не смогла предотвратить этот процесс саморазрушения, перспективы которого далеко еще не ясны. Однако ясно другое: как выразился влиятельный американский политический публицист Эд Бродоу, «помашем на прощание Америке, которую мы знали и любили!»².

\title{
Список литературы
}

Андреев И.А. 2020. «Мягкая сила» глазами зарубежных аналитиков: к операционализации концепта. - Вестник Института социологии РАН. № 3. С. 143154.

Емельянова Н.Н. 2015. Перспективы «гибкой власти» в Азии (на примере Китая и Индии). - Власть. Т. 23. № 6. С. 186-191.

Журавлева Е.В. 2016. Стратагема красотки: теории «мягкой силы» с китайской спецификой. - Вестник РУДН. Сер. Международные отношения. Т. 16. № 1. C. 17-31.

Тимофеев О.А. 2009. «Мягкие» методы международного влияния и трансформация внешнеполитической парадигмы в КНР. - Вестник Тихоокеанского государственного университета. № 4(15). С. 189-198.

ANDREEV Ivan Andreevich, Assistant at the Chair of Philosophy, Political Science and Sociology, National Research University «Moscow Power Engineering Institute» (14 Krasnokazarmennaya St, Moscow, Russia, 111250; v-andreev_07@ mail.ru)

\section{SOFT POWER IN THE WEST AND EAST: THE PROBLEM OF EFFICIENCY}

\begin{abstract}
The article discusses the issue of criteria that allow giving a comparative assessment of the soft power of different states. The founder of the theory of soft power J. Nye proceeded from the fact that the appeal of western liberal democracy is universal. Within the framework of this interpretation, the assessment of the soft power of any country is
\end{abstract}

\footnotetext{
${ }^{1}$ Fukuyama F. 2021. Rotten to the Core? How America's Political Decay Accelerated during the Trump Era. - Foreign Affairs. Jan. 18.

2 Brodow E. 2021. Waving Goodbye to the America We All Knew and Loved. - American Thinker.
} Jan. 6. 
essentially an assessment of the cultural and psychological distance between this country and the normative western models. Meanwhile, China basing on the concept of a powerful cultural state has developed its own alternative to the theories of J. Nye. This article proves the impossibility of a model of soft power suitable for all, because the practices of its application are determined by specific goals and objectives, which can differ very significantly from one state to another. In the light of this approach, the author compares the American and Chinese soft power strategies in terms of their effectiveness and dynamics. In particular, there is a decrease in the attractiveness of the United States and the strengthening of the "Soft" influence of China. The author notes that in the modern world a situation of a parallel dominance of states using soft power of various types is possible.

Keywords: political influence, soft power, country's image, international environment, political strategy

ГОМЕЛАУРИ Ангелина Сергеевна - аспирант факультета политологии Санкт-Петербургского государственного университета (199034, Россия, г. Санкт-Петербург, Университетская наб., 7-9; gomelauri@yandex.ru)

\title{
АРКТИЧЕСКИЕ ТРАНСФОРМАЦИИ: РОССИЯ ДЕКЛАРИРУЕТ «ЖЕСТКУЮ СИЛУ»
}

\begin{abstract}
Аннотация. Сквозь призму концепций «мягкой» и «жесткой» силы, предложенных американским политологом Дж. Наем в начале 1990-х гг., в статье анализируется декларируемый российским государством курс, избранный для защиты арктических интересов, которые в настоящее время приобрели большую значимость, т.к. Арктика является регионом, который хранит ценные ресурсы, обладание которыми становится предметом международных дискуссий, тем более что границы арктических владений все еще подвижны. Соответственно, актуальным становится вопрос, какими методами могут быть достигнуты арктические цели России. В сложившейся ситуации государство предпочло сделать ставку на «жесткую силу», что обусловлено напряженной ситуацией, сложившейся на международной арене.
\end{abstract}

Ключевые слова: «мягкая сила», «жесткая сила», Российская Федерация, Арктика

$\mathrm{A}$ рктика - регион, имеющий стратегически важные запасы ресурсов, была обречена стать центром пересечения геополитических интересов ряда государств, имеющих достаточные основания, чтобы вступить в борьбу за обладание арктическими богатствами. На данный момент границы Арктики не закреплены единым определением.

С 1920-х гг. Арктика разделена на 5 территориальных секторов между Россией, Канадой, США, Норвегией и Данией. Стоит, однако, отметить, что их границы периодически претерпевают изменения. Так, ратифицировав в 1997 г. Конвенцию по морскому праву, принятую в 1982 г., Российская Федерация пошла на компромисс с рядом зарубежных государств, потеряв при этом существенную часть акватории [Смирнов 2016: 11]. Указанная конвенция не решила все спорные вопросы вокруг арктических территорий. В 2010 г. Россия и Норвегия подписали договор о разграничении морских пространств, ставший результатом переговоров, длившихся в течение нескольких десятилетий: по условиям договора спорные территории в Баренцевом море и Северном Ледовитом океане были разделены на две равные части ${ }^{1}$, что привело к уступке Россией части акватории, принадлежавшей, согласно постановле-

1 Договор между Российской Федерацией и Королевством Норвегия о разграничении морских пространств и сотрудничестве в Баренцевом море и Северном Ледовитом океане. Доступ: http://www.kremlin.ru/supplement/707 (проверено 10.03.2021). 